\title{
Analisa Parkir Kendaraan Mobil Di Ruas Jalan Sentot Ali Basa Kecamatan Jambi Timur
}

\author{
Yayan Saputra*, Amsori M. Das, Darwani \\ Program Studi Teknik Sipil Universitas Batanghari Jambi \\ *Correspondence email: yayansaputra654321@gmail.com
}

\begin{abstract}
Abstrak. Tujuan dari penelitian ini adalah untuk mengetahui pengaruh kendaraan yang diparkir di jalan terhadap karakteristik arus lalu lintas pada jalan penumpang melalui studi kasus Jalan Sentot Ali Basa. Data yang akan dikumpulkan adalah survei lalu lintas berupa survei arus lalu lintas dan survei waktu tempuh kendaraan. Ada dua bagian dalam penelitian ini. Bagian pertama merupakan bagian jalan dengan kondisi jalan raya, dan tidak ada kendaraan yang parkir di jalan tersebut. Bagian kedua merupakan bagian dari ruas jalan Sebuah mobil yang diparkir di atas ruas jalan tersebut. Dengan membandingkan karakteristik arus lalu lintas pada kedua kondisi tersebut, maka dilakukan analisis pengaruh kendaraan parkir terhadap karakteristik arus lalu lintas. Hasil penelitian ini menunjukkan bahwa kendaraan yang diparkir di jalan akan berdampak pada karakteristik kecepatan dan karakteristik volume lalu lintas.
\end{abstract}

Kata Kunci: Kendaraan parkir, Karakteristik Arus Lalulintas.

\section{PENDAHULUAN}

Pembangunan fisik diwilayah perkotaan seperti pembangunan pertokoan, tempat pendidikan, dan berbagai bangunan lainya, telah mengakibatkan terjadinya perubahan tata guna lahan di sepanjang jalan perkotaan di kota Jambi. Kondisi lain dapat juga dilihat pada beberapa wilayah perkotaan di kota Jambi yaitu banyaknya terjadi perubahan tata guna lahan pada sisi kiri dan sisi kanan badan jalan yang belum diimbangi dengan penyediaan fasilitas parkir untuk kendaraan bermotor yang mencukupi pada ruas Jalan Sentot Ali Basa fasilitas pakirnya belum mencukupi bagi para pengunjung.

\section{METODE}

Dalam melakukan pengumpulan data lalulintas, dilakukan dengan cara menghitung secara manual. Perhitungan data volume lalulintas, data waktu tempuh kendaraan dan data volume kendaraan parkir pada badan jalan untuk kepentingan studi tugas akhir ini dipergunakan peralatan sebagai berikut :

1. Formulir survey, yang terdiri dari formulir survai volume lalulintas, formulir survey waktu tempuh kendaraan dan formulir survai parkir kendaraan roda empat pada badan jalan, dimana contoh formulir survai sebagaimana terlampir.

2. Meter dengan panjang 50 (lima puluh) meter, digunakan untuk mengukur geometri jalan, meliputi lebar struktur trotoar, lebar trotoar, dan panjang ruas jalan untuk mendapatkan data waktu tempuh kendaraan dan panjang jalan. detail lokasi perhitungan volume parkir Menit.

3. Mike board atau papan triplek Inilah yang menjadi dasar penulisan kuesioner.

4. Kamera adalah alat untuk merekam segala aktivitas dan kondisi di lokasi.

Data lain-lainnya yang dibutuhkan adalah data :

1. Data geometrik ruas jalan, meliputi panjang jalan, lebar trotoar, lebar lajur, lebar dan jumlah lajur, dan lebar bahu jalan.

2. Data kelompok kendaraan dan volume tiap kelompok kendaraan pada setiap periode pengamatan. Data ini digunakan untuk menentukan arus maksimum atau arus lalu lintas jam puncak untuk setiap periode pengamatan (jam puncak pagi, siang, sore, dan malam).

3. Data waktu tempuh kendaraan sepanjang ruas STA.0 + 250 meter yang digunakan untuk menghitung rata-rata kecepatan ruang (Us) arus lalu lintas di ruas jalan tersebut pada setiap jam puncak pada pagi, siang, sore dan malam.

4. Data tentang kendaraan roda empat yang parkir di kiri kanan jalan sepanjang STA.0 + 500 meter keluar masuk. Data ini digunakan untuk menghitung dan menganalisis pengaruh kecepatan udara rata-rata (Us) akibat pengurangan lebar jalan efektif.

Data volume lalulintas dan waktu tempuh kendaraan tersebut dikelompokan menurut kelompok kendaraan yang terdiri atas :

1. Kelompok kendaraan ringan (KR) yang terdiri dari kendaraan bermotor roda 4 (empat). 
2. Kelompok kendaraan berat (KB) yang terdiri dari kendaraan bermotor roda 6 (enam).

3. Kelompok kendaraan sepeda motor (SMP) yaitu kendaraan bermotor beroda 2 (dua) atau beroda 3 (tiga).

\section{HASIL DAN PEMBAHASAN}

Jl. Sentot Ali Basa di Kabupaten Jambi Timur terbentang dari utara ke selatan dan selatan ke utara. Berdasarkan hasil pengukuran geometrik ruas jalan lokasi studi yang meliputi panjang jalan, lebar trotoar, lebar jalur lalu lintas, lebar dan jumlah jalan raya, serta lebar saluran drainase diperoleh hasil sebagai berikut :

Tabel 1. Geometrik ruas Jl. Sentot Ali Basa Kecamatan Jambi Timur

\begin{tabular}{|c|c|c|c|c|c|c|}
\hline Nama Jalan & Panjang & \multicolumn{5}{|c|}{ Lebar Bagian Jalan (Meter) } \\
\cline { 3 - 7 } & Jalan (M) & Aspal & Lajur Lalulintas & Bahu Jalan & Trotoar & Drainase \\
\hline Jl.Sentot Ali Basa & 1.700 & 8 & $2 \times 4$ & $2 \times 0,6$ & Tidak Ada & Tidak Ada \\
\hline
\end{tabular}

Sumber : Hasil Pengukuran, 2020

Penampang dan tampilan atas jalan. Berdasarkan hasil pengukuran yang telah dilakukan, Sentot Ali Basa di Jambi Timur dapat menjelaskan sebagai berikut:

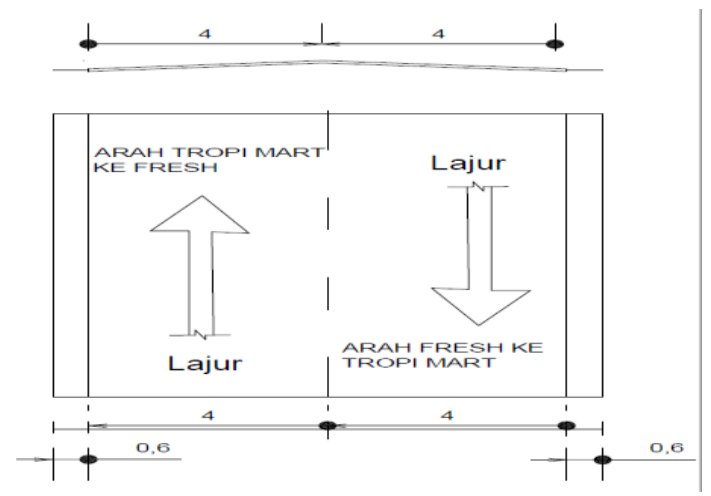

Gambar 2. Potongan Melintang Jl. Sentot Ali Basa Kecamatan Jambi Timur

Sumber: Hasil pengukuran di Lapangan, 2020

Marka jalan yang berfungsi untuk pemisah arah lalulintas yang terletak pada bagian tengah badan jalan merupakan garis ganda yang terdiri dari garis lurus terputus-putus dan garis lurus tidak terputus-putus, jika dilihat dari arah tropi mart menuju fresh maka letak garis terputus-putus ada pada sisi kiri dan garis tidak terputus ada pada sisi kanan dengan lebar garis $10 \mathrm{~cm}$ baik untuk garis terputus-putus dan garis lurus serta panjang garis terputus-putus 2,00 $\mathrm{m}$.

Dan terdapat kemacetan pada pengamatan studi ini pada ruas Jl. Sentot Ali Basa Kecamatan Jambi Timur pada saat kendaraan menikung atau memutar pada bagian ruas jalan yang terputus seperti gambar berikut:

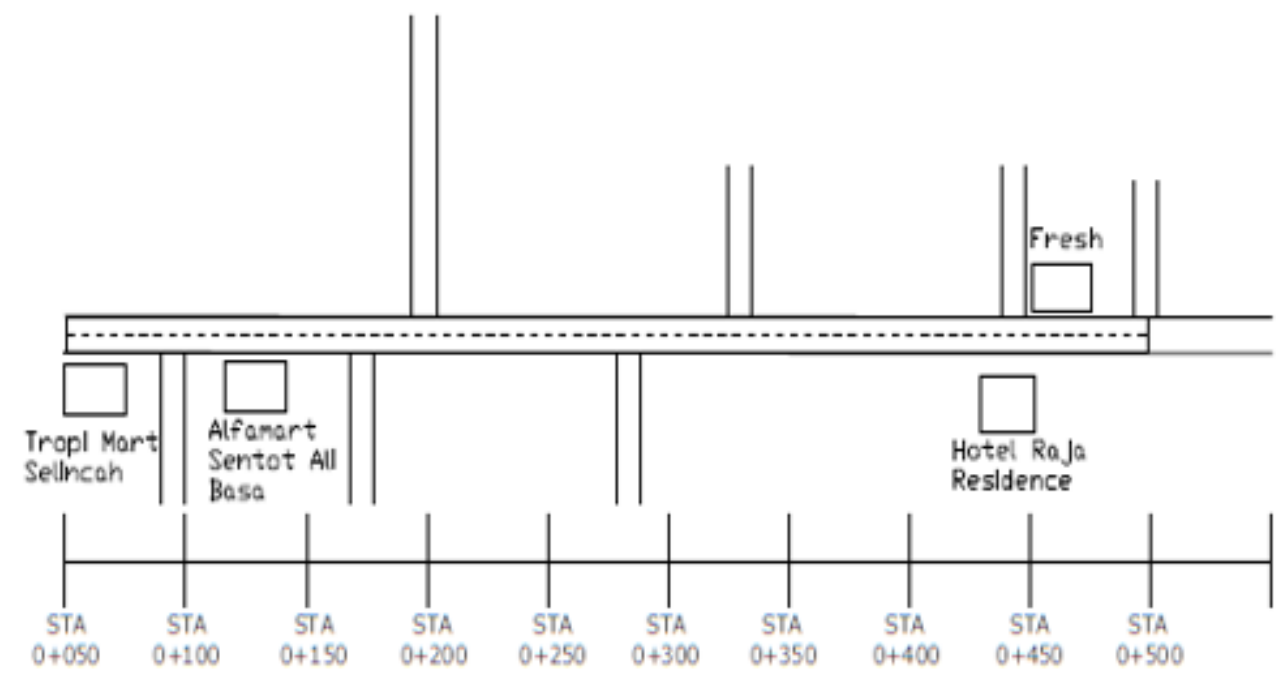

Gambar 3. Denah Ruas Jl. Sentot Ali Basa Kecamatan Jambi Timur

Sumber: Hasil pengamatan di Lapangan, 2020 


\section{Volume Lalulintas}

Berdasarkan hasil survei 3 hari (tiga) hari, volume lalu lintas pada hari tersibuk adalah 22 Agustus (Sabtu), 23 (Minggu) dan Senin, 2020 yang berlangsung selama 8 jam, termasuk jam sibuk pagi hari pada pukul 08.00-11.00 WIB atau pukul 3 (tiga) jam, jam sibuk siang hari adalah 13.0-15.00 WIB atau 2 (dua) jam, kemudian jam sibuk siang hari adalah 16.00-17.00 WIB, atau 1 (satu) jam, dan malam 19: 00-21.00 WIB sibuk 1 jam, atau 2 (dua) jam berturut-turut, dengan menghitung secara manual masing-masing jenis atau kelompok kendaraan, dan setelah dilakukan analisa dan penghitungan data survey didapatkan volume lalu lintas Jalan Sentot Ali Basa. Seperti yang ditunjukkan pada tabel di bawah ini.

1. Sepeda Motor emp $=0,4$

2. Kendaraan Ringan (KR) emp $=1,0$

3. Kendaraan Berat $(\mathrm{KB}) \mathrm{emp}=1,3$

Selain itu, berdasarkan volume lalu lintas kendaraan per jam digunakan perhitungan faktor emp untuk mendapatkan volume lalu lintas dalam satuan smp / jam. Volume lalu lintas dari satuan kendaraan / jam ke satuan smp / jam dapat dihitung dengan cara mengalikan jumlah hasil survey dengan koefisien emp. Sebagai contoh perhitungan berikut ini untuk periode jam survey 08.00-09.00 WIB. Berikut hasilnya adalah diperoleh:

Tabel 2. Jumlah Smp/jam

\begin{tabular}{|l|l|c|c|}
\hline NO & \multicolumn{1}{|c|}{ Kendaraan } & Jumlah kend x emp & $\begin{array}{c}\text { Hasil Jumlah } \\
\text { Smp/Jam }\end{array}$ \\
\hline 1 & Sepeda Motor & $877 \times 0,4$ & 350,8 \\
\hline 2 & Kendaraan Ringan & $312 \times 1,0$ & 312 \\
\hline 3 & Kendaraan Bus & $0 \times 1,3$ & 0 \\
\hline 4 & Kendaraan Truk & $13 \times 1,3$ & 16,9 \\
\hline \multicolumn{2}{|c}{ Jumlah } & 1202 & 876 \\
\hline
\end{tabular}

Sumber: Hasil Penelitian, 2020

Tabel 3. Volume Lalulintas Ruas Jalan Sentot Ali Basa Pada Arah Fresh Menuju Tropi Mart

\begin{tabular}{|c|c|c|c|c|c|c|}
\hline \multirow{2}{*}{ Waktu Survey } & \multicolumn{2}{|c|}{ Jenis/kelompok dan jumlah kendaraan } & \multicolumn{2}{c|}{ Volume Lalulintas } \\
\cline { 2 - 7 } & $\begin{array}{c}\text { Sepeda } \\
\text { Motor }\end{array}$ & $\begin{array}{c}\text { Kend } \\
\text { Ringan }\end{array}$ & $\begin{array}{c}\text { Kend } \\
\text { Bus }\end{array}$ & $\begin{array}{c}\text { Kend } \\
\text { Truk }\end{array}$ & Kend/Jam & Smp/Jam \\
\hline $08.00-09.00$ & 877 & 312 & 0 & 13 & 1202 & 793 \\
\hline $09.00-10.00$ & 967 & 214 & 0 & 23 & 1204 & 1383 \\
\hline $10.00-11.00$ & 852 & 189 & 0 & 21 & 1062 & 1257 \\
\hline $13.00-14.00$ & 803 & 344 & 0 & 10 & 1157 & 1442 \\
\hline $14.00-15.00$ & 1124 & 463 & 0 & 19 & 1606 & 896 \\
\hline $16.00-17.00$ & 1360 & 730 & 0 & 18 & 2108 & 936 \\
\hline $19.00-20.00$ & 2160 & 897 & 0 & 18 & 3075 & 1297 \\
\hline $20.00-21.00$ & 2560 & 1104 & 0 & 14 & 3678 & 1787 \\
\hline
\end{tabular}

Sumber: Hasil survey dan analisa data, 2020

Tabel 4. Volume Lalulintas Ruas Jalan Sentot Ali Basa Pada Arah Tropi Mart Menuju Fresh

\begin{tabular}{|c|c|c|c|c|c|c|}
\hline \multirow[b]{2}{*}{ Waktu Survey } & \multicolumn{4}{|c|}{ Jenis/kelompok dan jumlah kendaraan } & \multicolumn{2}{|c|}{ Volume Lalulintas } \\
\hline & $\begin{array}{l}\text { Sepeda } \\
\text { Motor }\end{array}$ & $\begin{array}{c}\text { Kend } \\
\text { Ringan }\end{array}$ & $\begin{array}{c}\text { Kend } \\
\text { Bus }\end{array}$ & $\begin{array}{l}\text { Kend } \\
\text { Truk }\end{array}$ & Kend/Jam & Smp/Jam \\
\hline $08.00-09.00$ & 580 & 290 & 0 & 15 & 885 & 541 \\
\hline $09.00-10.00$ & 1030 & 745 & 0 & 20 & 1795 & 1183 \\
\hline $10.00-11.00$ & 1145 & 660 & 0 & 15 & 1820 & 1137 \\
\hline $13.00-14.00$ & 1225 & 710 & 0 & 12 & 1947 & 1215 \\
\hline $14.00-15.00$ & 1375 & 523 & 0 & 15 & 1913 & 1079 \\
\hline $16.00-17.00$ & 1720 & 623 & 0 & 22 & 2365 & 1339 \\
\hline $19.00-20.00$ & 1390 & 207 & 0 & 7 & 1604 & 1314 \\
\hline $20.00-21.00$ & 1128 & 820 & 0 & 22 & 1970 & 772 \\
\hline
\end{tabular}

Sumber: Hasil survey dan analisa data, 2020 
Yayan Saputra, Amsori M. Das dan Darwani, Analisa Parkir Kendaraan Mobil Di Ruas Jalan Sentot Ali Basa Kecamatan Jambi Timur

Tabel 5. Volume Lalulintas Ruas Jl. Sentot Ali Basa Untuk 2 (dua) Arah

\begin{tabular}{|c|c|c|c|c|c|c|}
\hline \multirow{2}{*}{ Waktu Survey } & \multicolumn{2}{|c|}{ Jenis/kelompok dan jumlah kendaraan } & \multicolumn{2}{c|}{ Volume Lalulintas } \\
\cline { 2 - 7 } & $\begin{array}{c}\text { Sepeda } \\
\text { Motor }\end{array}$ & $\begin{array}{c}\text { Kend } \\
\text { Ringan }\end{array}$ & $\begin{array}{c}\text { Kend } \\
\text { Bus }\end{array}$ & $\begin{array}{c}\text { Kend } \\
\text { Truk }\end{array}$ & Kend/Jam & Smp/Jam \\
\hline $08.00-09.00$ & 1457 & 602 & 0 & 28 & 2087 & 1344 \\
\hline $09.00-10.00$ & 1997 & 959 & 0 & 43 & 2999 & 2566 \\
\hline $10.00-11.00$ & 1997 & 849 & 0 & 36 & 2882 & 2395 \\
\hline $13.00-14.00$ & 2028 & 1054 & 0 & 22 & 3104 & 2657 \\
\hline $14.00-15.00$ & 2499 & 986 & 0 & 34 & 3519 & 1988 \\
\hline $16.00-17.00$ & 3080 & 1353 & 0 & 40 & 4473 & 2276 \\
\hline $19.00-20.00$ & 3550 & 1104 & 0 & 25 & 4679 & 2611 \\
\hline $20.00-21.00$ & 3688 & 1924 & 0 & 36 & 5648 & 3445 \\
\hline
\end{tabular}

Sumber: Hasil survey dan analisa data, 2020

Berdasarkan hasil survei dan analisis data yang ditunjukkan pada tabel, dapat diketahui komposisi arus lalu lintas di Jl. Sentot Ali Basa yang paling penting kendaraannya adalah Sepeda Motor (SM) dan Kendaraan Ringan (KR) Sentot Ali Basa. Perbandingan rata-rata antara ketiga kelompok kendaraan tersebut adalah sebagai berikut:

$\frac{\text { Jumlah kendaraan }}{\text { Jumlah keseluruhan }}$ 100\%

1. Sepeda Motor $(\mathrm{SM})=69,05 \%$

2. Kendaraan Ringan (KR) $=30,05 \%$

3. Kendaraan Bus $=0,00 \%$

4. Kendaraan Besar $=0,90 \%$

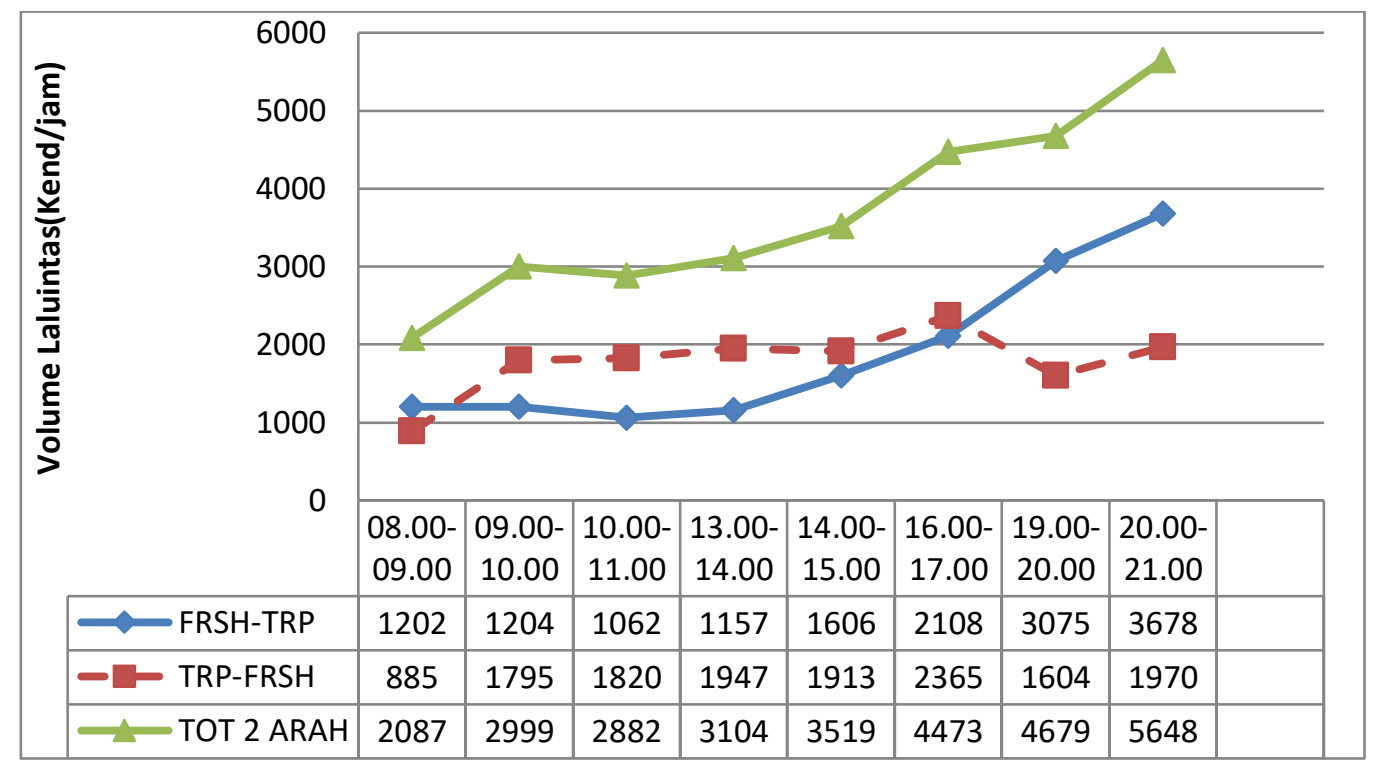

Sumber: Hasil Penelitian, 2020

Gambar 4. Grafik fluktuasi arus lalulintas dalam kend/jam 


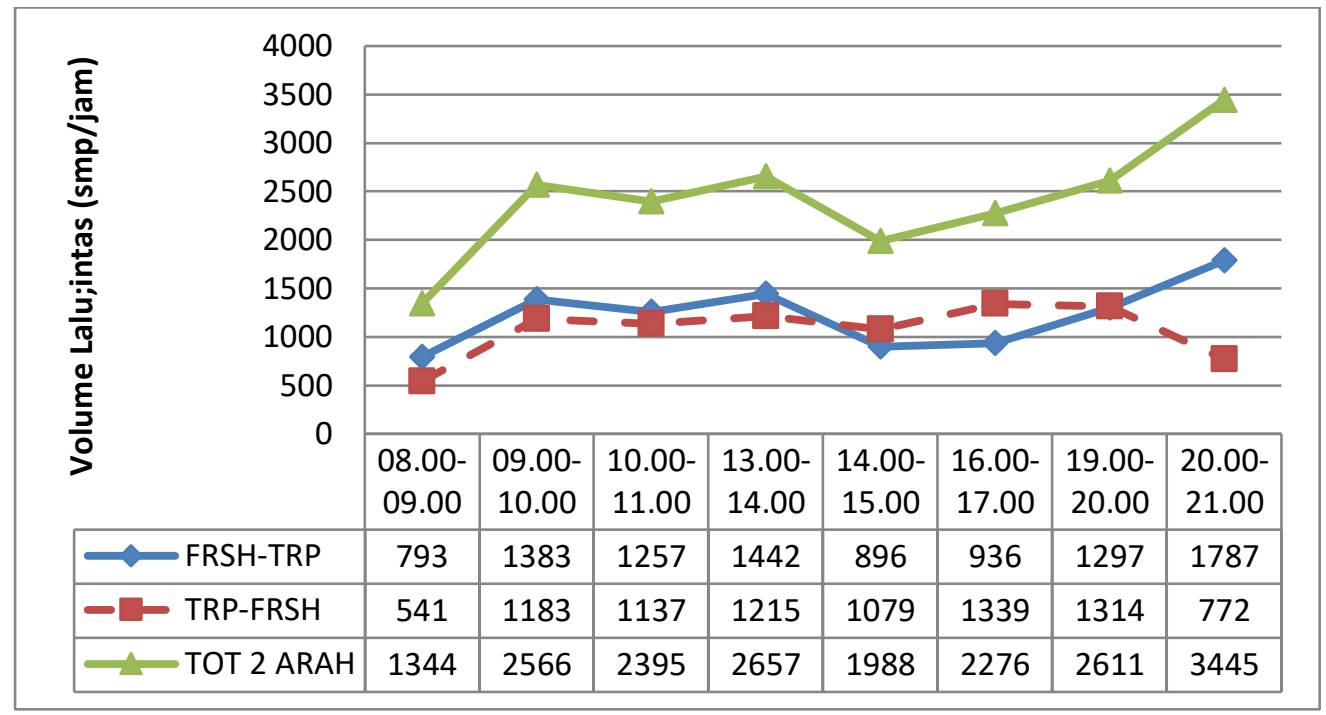

Sumber: Hasil Penelitian, 2020

Gambar 5. Grafik fluktuasi arus lalulintas dalam smp/jam

Keterangan:

FRSH : Fresh

TRP : Tropi

Tabel 6. Kecepatan rata-rata ruang (Us) arus lalulintas diruas Jl. Sentot Ali Basa pada beberapa jam puncak

\begin{tabular}{|c|l|c|c|c|c|}
\hline \multirow{2}{*}{ Ruas Jalan } & \multicolumn{1}{|c|}{ Arah Lalulintas } & \multicolumn{3}{|c|}{ Kecepatan Rata-rata Ruang (Us) (Km/jam) } \\
\cline { 3 - 6 } Jalan Sentot Ali & Pagi & Siang & Sore & Malam \\
\hline Basa & Mresh - Tropi Mart & & & & \\
Kec. Jambi Timur & Minimum & 20 & 21 & 25 & 25 \\
& Maksimum & 30 & 22 & 30 & 35 \\
\cline { 2 - 6 } & Tropi Mart - Fresh & 20 & 20 & 25 & 25 \\
& Minimum & 35 & 25 & 30 & 35 \\
\hline
\end{tabular}

Sumber: Hasil Analisa Data, 2020

\section{Kecepatan Arus Lalulintas}

Dengan hasil penelitian tabel diatas dengan adanya kendaraan yang parkir pada badan jalan mengakibatkan kecepatan rata-rata pada kecepatan kendaraan pada jam puncak pagi hari dapat mencapai $20 \mathrm{~s} / \mathrm{d} 35 \mathrm{~km} / \mathrm{jam}$, dan pada jam puncak siang hari dapat mencapai $20 \mathrm{~s} / \mathrm{d} 25 \mathrm{~km} / \mathrm{jam}$, pada jam puncak sore hari dapat mencapai kecepatan $25 \mathrm{~s} / \mathrm{d}$ $30 \mathrm{~km} / \mathrm{jam}$, jam puncak kemacetan pada malam hari mencapai kecepatan $25 \mathrm{~s} / \mathrm{d} 35 \mathrm{~km} / \mathrm{jam}$. Sedangkan dengan kecepatan rata-rata jika tidak adanya kendaraan yang parkir pada badan jalan kecepatan kendaraan mencapai kecepatan pada normalnya dengan mencapai $40 \mathrm{~s} / \mathrm{d} 50 \mathrm{~km} / \mathrm{jam}$ pada setiap jam-jam puncaknya.

\section{Kepadatan Lalulintas}

Untuk menghitung kepadatan lalulintas yang terjadi pada ruas Jalan Sentot Ali Basa Kec. Jambi timur, maka dihitung kepadatan lalulintas untuk total 2 (dua) arah, hal ini dikarnakan tipe Jalan Sentot Ali Basa adalah 2/2 D. Selanjutnya hasil perhitungan kepadatan lalulintas ruas Jalan Sentot Ali Basa yaitu sebagai berikut

Tabel 7. Kepadatan Arus Lalulintas di Ruas Jalan Sentot Ali Basa Pada Beberapa Jam Puncak

\begin{tabular}{|l|c|c|c|c|}
\hline \multirow{2}{*}{ Arah Lalulintas } & \multicolumn{4}{|c|}{ Kepadatan Lalulintas (smp/km) } \\
\cline { 2 - 5 } Total 2 Arah & Pagi & Siang & Sore & Malam \\
\hline Minimum & 13,44 & 19,88 & 25,59 & 33,12 \\
Maksium & 25,66 & 26,57 & 34,45 & 35,43 \\
\hline
\end{tabular}

Sumber: Hasil Analisa Data, 2020

Berdasarkan hasil survei volume lalu lintas pada jam-jam sibuk pagi, siang, dan malam, dapat diperoleh hasil yang minimal dan maksimal, dimana kepadatan kendaraan pada pagi hari kurang padat dibandingkan dengan jam sibuk pada sore hari. 


\section{Parkir Kendaraan Pada Badan Jalan}

Peggunaan tepi jalan yaitu lajur paling pinggir disepanjang Jalan Sentot Ali Basa dengan panjang segmen jalan dari STA 0+000 s/d STA 0+ 500 yang dipantau yaitu sepanjang $500 \mathrm{M}$ pada kedua sisi (kiri dan kanan) sebagai tempat parkir kendaraan roda 4 oleh setiap pengunjung pertokoan dan Toserba yang berada pada sepanjang ruas Jalan Sentot Ali Basa adalah sebagaimana terlampir pada tabel berikut:

Tabel 8. Jumlah dan lama waktu parkir kendaraan roda empat pada tepi Jalan Sentot Ali Basa pada beberapa jam puncak

\begin{tabular}{|c|c|c|c|c|}
\hline \multirow{2}{*}{ Jam puncak } & $\begin{array}{c}\text { Jumlah kendroda 4 } \\
\text { yang parkir } \\
\text { (kend/jam/250m) }\end{array}$ & Minimum & Maksimum & Rata-rata \\
\cline { 3 - 5 } & 45 & 5 & 12 & 8,5 \\
\hline Pagi hari & 61 & 5 & 25 & 17,5 \\
\hline Siang hari & 113 & 8 & 17 & 16,5 \\
\hline Sore hari & 93 & 7 & 15 & 15,7 \\
\hline Sore Malam & \multicolumn{3}{|c|}{} \\
\hline
\end{tabular}

Sumber: Hasil Analisa Data, 2020

Terlihat dari tabel di atas bahwa jumlah dan lamanya waktu parkir kendaraan roda empat di pinggir jalan pada jam sibuk pagi dan siang lebih kecil dibandingkan jam sibuk siang atau malam hari. Seperti kita ketahui bersama, pada jam sibuk sore hari jumlah kendaraan parkir di pinggir jalan semakin meningkat, dan lamanya waktu parkir juga semakin bertambah, yang juga menunjukkan bahwa aktivitas dan aktivitas masyarakat sekitar lokasi studi semakin meningkat.

\section{Pengaruh Parkir Pada Badan Jalan Terhadap Kecepatan}

Pada pengaruh kendaraan parkir dibadan jalan terhadap kecepatan dibutuhkan data hasil survey yang mana data ini akan diolah untuk mendapatkan hubungan matematis antara kecepatan rata - rata dengan kendaraan parkir. Dengan hasil survey seperti tabel berikut ini :
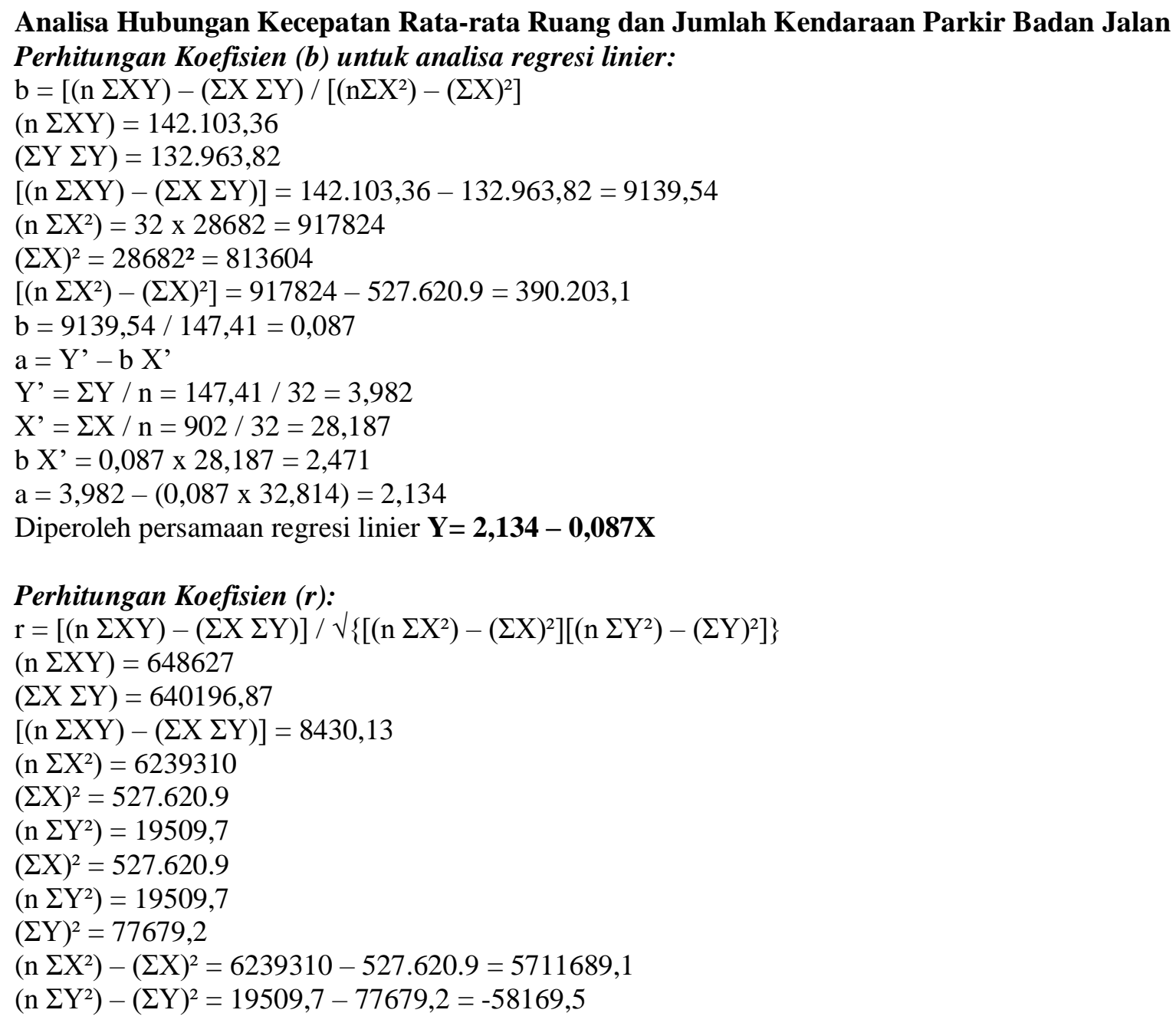
$\sqrt{ }\left\{\left[\left(\mathrm{n} \Sigma \mathrm{X}^{2}\right)-(\Sigma \mathrm{X})^{2}\right]\left[\left(\mathrm{n} \Sigma \mathrm{Y}^{2}\right)-(\Sigma \mathrm{Y})^{2}\right]\right\}=6847679,7$

$\mathrm{r}=0,512$

$\mathrm{r}^{2}=0,262 \times 100$

$\mathrm{r}^{2}=26,2 \%$

Analisa hubungan antara banyaknya kendaraan parkir pada badan jalan terhadap kecepatan arus lalulintas dihitung berdasarkan analisa regresi linear, dimana hasilnya adalah sebagaimana gambar berikut :

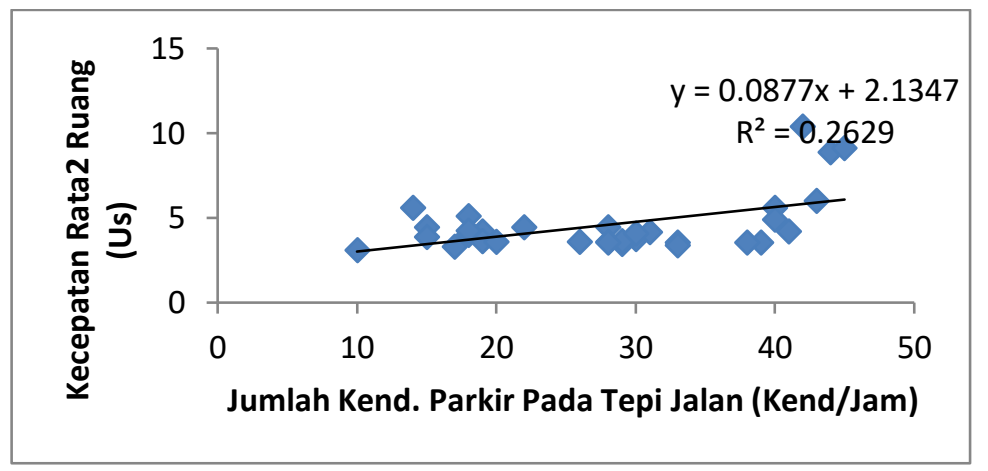

Sumber: Hasil Penelitian, 2020

Gambar 6. Hubungan Kecepatan dan Jumlah Kendaraan Parkir

Yang mana hasil grafik regresi linier untuk menentukan nilai $\mathrm{R}$ dimana $\mathrm{R}$ adalah suatu gabungan dari dua variabel secara kuantitatif dimana variabel tersebut yaitu $\mathrm{Y}$ variabel terikat dan $\mathrm{X}$ variabel bebas.

Kegunaan grafik linier yang ada diatas untuk melakukan atau menentukan prediksi berdasarkan data-data hasil lapangan yang telah diamati.

\section{Kinerja Ruas Jalan Pada Kondisi Saat Ini}

Kinerja jalan dihitung sesuai dengan "Manual Kapasitas Jalan Indonesia" (MKJI, 1997), dimana parameter yang akan ditinjau adalah rasio (rasio) volume terhadap kapasitas (Q / C ratio).

Kapasitas ruas jalan dihitung dengan persamaan:

C = Co x FCw x FCsp x FCsf x FCes (smp/jam)

Dimana :

$\mathrm{C}=$ Kapasitas dalam smp/jam

Co = Kapasitas dasar dalam smp/jam (Tabel 2.9)

$\mathrm{FCw}=$ Faktor penyesuaian lebar jalur LL (Tbel 2.10)

FCsp $=$ Faktor penyesuaian pemisah arah $($ Tabel 2.11)

FCsf $=$ Faktor penyesuaian hambatan samping (Tabel 2.12)

$\mathrm{FCcs}=$ Faktor penyesuaian ukuran kota (Tabel 2.14)

\section{Perhitungan Kapasitas ruas jalan}

Perhitungan kapasitas untuk ruas Sentot Ali Basa sebagaimana berikui ini :

$\mathrm{C}=\mathrm{Co} \times \mathrm{FCw} \times \mathrm{FCsp} \times \mathrm{FCsf} \times \mathrm{FCcs}(\mathrm{smp} / \mathrm{jam})$

$\mathrm{C}=2900 \times 1,14 \times 1 \times 0,86 \times 0,94$

$\mathrm{C}=2673$

Dengan jumlah lajur Efektif adalah 2 lajur, maka untuk mencari $\mathrm{C}$ total smp/jam, adalah :

$\mathrm{C}$ total smp/jam $=\mathrm{C}$ smp/jam $\times 2$

$2673 \times 2=5345,141$

Dari tabel perhitungan diatas diketahui bahwa kapasitas efektif untuk ruas Jalan Sentot Ali Basa adalah $5345,141 \mathrm{smp} / \mathrm{jam}$, dengan demikian nilai Q/C rasio untuk lalulintas 2 (dua) arah dapat dihitung sebagai berikut :

1. Periode jam puncak pagi $\mathrm{Q} / \mathrm{C}=2566 / 2673=0,960$

2. Periode jam puncak siang $\mathrm{Q} / \mathrm{C}=2657 / 2673=0,994$

3. Periode jam puncak sore $\mathrm{Q} / \mathrm{C}=2276 / 2673=0,852$

4. Periode jam puncak malam $\mathrm{Q} / \mathrm{C}=3445 / 2673=1,289$ 

yaitu:

Untuk menentukan performa jalan, parameter selanjutnya yang harus dihitung adalah kecepatan arus bebas FV $=($ Fvo + FVw $) \times$ FFVes $x$ FFsf $(\mathrm{km} /$ jam $)$

$\mathrm{FV}=$ Kecepatan arus bebas kend ringan pad kend lapangan $(\mathrm{km} / \mathrm{jam})$

$\mathrm{FVo}=$ Kecepatan arus bebas dasar kend ringan (Tabel 2.4)

$\mathrm{FVw}=$ Penyesuaian kecepatan untuk lebar jalan (Tabel 2.5)

FFVsf $=$ Faktor penyesuaian untuk hambatan samping dan kereb (Tabel 2.7)

$\mathrm{FFVcs}=$ Faktor penyesuaian untuk kota $($ Tabel 2.8)

\section{Perhitungan kecepatan arus bebas}

Perhitungan kineja ruas jalan adalah kecepatan arus bebas, sebagaimana berikut :

$\mathrm{FV}=(\mathrm{Fvo}+\mathrm{FVw}) \times \mathrm{FFV}$ cs $\mathrm{FFsf}(\mathrm{km} / \mathrm{jam})$

$\mathrm{FV}=(42+0,73) \times 0,85 \times 1,14$

$\mathrm{FV}=41,14$

Dari hasil perhitungan diatas diperoleh kecepatan arus bebas (FV) pada ruas Jalan Sentot Ali Basa adalah 41,41 $\mathrm{km} / \mathrm{jam}$, dan kecepatan rata-rata ruang pada setiap jam puncak adalah :

1. Periode jam puncak pagi Us $=20-35 \mathrm{~km} / \mathrm{jam}$

2. Periode jam puncak siang Us $=20-25 \mathrm{~km} / \mathrm{jam}$

3. Periode jam puncak sore $U s=25-30 \mathrm{~km} / \mathrm{jam}$

4. Periode jam puncak malam Us $=25-35 \mathrm{~km} / \mathrm{jam}$

Berdasarkan hasil analisis Q / C ratio, kepadatan lalu lintas, kecepatan rata-rata, dan kecepatan arus bebas di Jalan Sentot Ali Basa diketahui tingkat pelayanan jalan tersebut saat ini pada kondisi pagi dan sore hari. Terletak di tingkat layanan "D", di mana "aliran mendekati tidak stabil, kecepatan masih terkontrol, dan Q / C masih dapat ditoleransi", kondisi siang dan malam berada pada tingkat layanan "E", di mana "volume aliran mendekati atau mencapai batas, arusnya tidak stabil, Kecepatan terkadang berhenti. "

\section{SIMPULAN}

Berdasarkan dari hasil data yang diambil dilapangan dan diolah pada perhitungan sebelumnya maka didapatkan kesimpulan sebagai berikut :

1. Pada survey pengumpulan data pada jam-jam puncak pada ruas Jalan Sentot Ali Basa mendapatkan hasil dimana kendaraan yang parkir pada badan jalan mencapai 45 kendaraan, pada jam puncak pagi hari, 61 kendaraan pada jam puncak siang, 113 kendaraan pada jam puncak sore hari, dan 93 kendaraan pada jam puncak malam hari dengan jumlah kendaraan parkir yang telah didapat mengakibat kan kecepatan kendaraan bermotor menurun dengan kecepatan maksimum $30 \mathrm{~km} / \mathrm{jam}$ sampai dengan $35 \mathrm{~km} / \mathrm{jam}$, pada kecepatan minimum mencapai 20 $\mathrm{km} / \mathrm{jam}$ sampai dengan $25 \mathrm{~km} / \mathrm{jam}$. Pengaruh kendaraan dibadan jalan sebesar 26,2\% terhadap kecepatan rata-rata pada jalan Sentot Ali Basa

2. Dari hasil analisa regresi linear didapat hubungan matematis yaitu: $Y=2,134-0,087 X$ dimana $Y$ adalah kecepatan rata - rata dan $\mathrm{X}$ adalah kendaraan parkir. Hubungan matematis ini menjelaskan besaran nilai dari Variabel $\mathrm{X}$ terhadap nilai Variabel Y

3. Pada kecepatan kendaraan diruas Jalan Sentot Ali Basa atau jalan kolektor primer dengan tidak adanya hambatan, atapun kendaraan parkir disisi bahu jalan mencapai $40 \mathrm{~km} / \mathrm{jam}$ sampai dengan $50 \mathrm{~km} / \mathrm{jam}$, sedangkan yang terjadi diruas Jalan. Sentot Ali Basa saat ini dengan adanya kendaraan yang parkir pada badan jalan mengakibat kan pengaruh kecepatan kendaraan menurun mencapai 20 km/jam sampai dengan 35 km/jam.

\section{Saran}

Untuk dapat mengurangi kemacetan ataupun mengurangi kepadatan kendaraan parkir pada bahu jalan dapat disarankan sebagai berikut :

1. Pada kondisi siang sampai malam hari dapat diatur lebih baik lagi kendaraan yang parkir pada badan jalan, dan jika terpaksa untuk parkir disisi bahu jalan, gunakan hanya 1 (satu) sisi saja agar tidak terlalu memperlambat laju kendaraan

2. Lebih memperluas lahan parkir pada setiap bangunan seperti pertokoan, sekolah dan pusat perbelanjaan yang meliputi sepanjang Jalan Sentot Ali Basa 
3. Jika terpaksa (dalam keadaan darurat) biasa memarkirkan kendaraan dibahu jalan dengan waktu yang tidak lama dan pengemudi harus berada didekat kendaraan.

4. Masyarakat harus ada edukasi tentang peraturan lalulintas, agar dapat menciptakan budaya tata tertib lalulintas dan keselamatan dalam berkendaraan pada arus lalulintas.

\section{DAFTAR PUSTAKA}

Hobb, FD, 1995, Perencanaan dan Teknik Lalulintas, (terjemahan) Gadjah Mada Universitas, Yogyakarta

Iskandar Abubakar (1999), Rekyasa Lalulintas, Pedoman Perencanaan dan Pengoprasian Lalulintas di Wilayah Perkotaan, Ditjen Perhubungan Darat, Depertemen Perhubungan RI, Jakarta

Iskandar Abubakar (1996) Menuju Lalulintas dan Angkutan Jalan Yang Tertib, Ditjen Perhubungan Darat, Depertemen Perhubungan RI, Jakarta

Keputusan Direktur Jendral Perhubungan Darat Nomor: 272/HK.105/DRJD/96 Tentang Pedoman Teknis Penyelengaraan Fasilitas Parkir Tahun 1996

Ditjen. Bina Marga Depertemen Perkerjaan Umum RI. 1997. Manual Kapasitas Jalan Indonesia. Jakarta

Marolok, Edward.K. 1995 Perencanaan dan Teknik Lalulintas. Diterjemahkan oleh Suprapto TM dan Waldijino, Gadjah Mada University, Yogyakarta

Munawar, 1998. Manajemen Lalulintas, Gadjah Mada Universitas, Yogyakarta

Peraturan Pemerintah RI No. 43 Tahun 1993 Tentang Prasarana dan Sarana Lalulintas Jalan, Sekretariat Negara RI, Jakarta

Undang-undangan Republik Indonesia NO. 38 Tahun 2004 Tentang Jalan, Sekretariat Negara RI, Jakarta 